\section{Polyp as a Complication of Argon Plasma Coagulation in Watermelon Stomach}

Gastric antral vascular ectasia (GAVE), or watermelon stomach, is an uncommon cause of gastrointestinal blood loss and iron-deficiency anaemia, that usually requires periodic blood transfusions. Endoscopic treatments, including endoscopic sclerotherapy, coagulation with Nd:YAG and argon lasers, argon plasma coagulation (APC), heater probe therapy, cryotherapy, and monopolar and multipolar electrocoagulation, are now the approaches of choice [1]. They are effective and safe, reducing transfusion requirements in these patients, although some complications have been reported [2-4].

We report an uncommon complication in a patient with GAVE that had been treated by APC.

A 75-year-old woman, with liver cirrhosis and portal hypertension associated with the hepatitis $\mathrm{C}$ virus, had experienced several episodes of anemia (hematocrit below 20\%; normal range 36\%-47\%) in the previous 10 months, without macroscopic signs of bleeding. Despite oral iron supplementation, she required eight blood transfusions in this period. Upper endoscopy revealed a typical image of watermelon stomach, with visible columns of vessels traversing the antrum in longitudinal folds and converging in the pylorus (Figure 1), and thus APC treatment was given. Four sessions of APC were required to avoid the need for transfusion. During the last upper endoscopy we observed a peduncular polyp in the previously treated area (Figure 2 ). This was removed by polypectomy and histopathological examination showed it to be a hyperplastic polyp.

Although endoscopic treatments for GAVE are safe and effective, some complications have been described. Reported complications of Nd:YAG laser treatment include antral strictures, perforations, development of hyperplastic polyps, and a case of gastric multifocal neoplasia [2-3]. Although such complications are uncommon after APC treatment, antral stricture

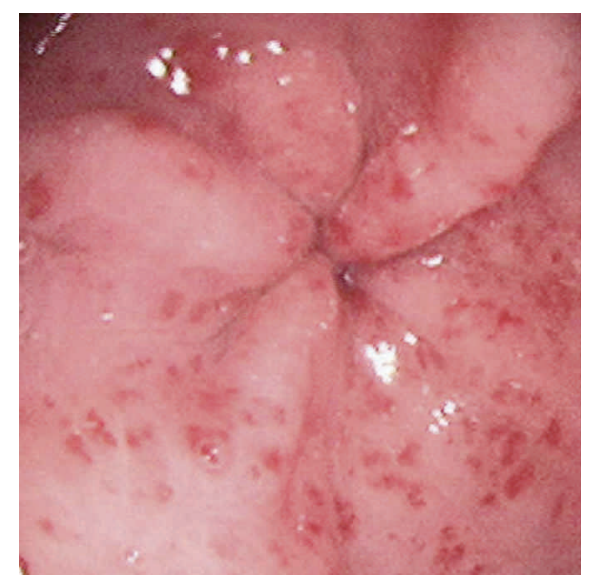

Figure 1 Endoscopic appearance of the gastric antrum in a patient with watermelon stomach.

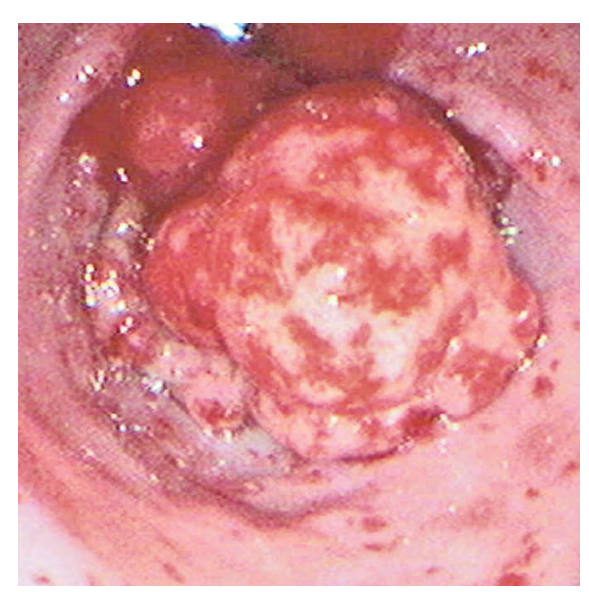

Figure 2 A hyperplastic polyp developed after multiple sessions of argon plasma coagulation.

$[4,5]$ and a case of hyperplastic polyp (DM Chaves, personal communication cited in [1]) have been reported following APC. Even though the development of a hyperplastic polyp more usually occurs after Nd:YAG laser treatment, we must consider this possibility when we observe a polyp after APC treatment in a patient with GAVE.
S. Izquierdo ${ }^{1}$, E. Rey ${ }^{1}$, A. Gutiérrez del Olmo², C. Almansa', J. Andrés Ramírez Armengol'2, M. Díaz-Rubio'

${ }^{1}$ Digestive Disease Service, Hospital Clínico San Carlos, Madrid, Spain

2 Endoscopy Service, Hospital Clínico San Carlos, Madrid, Spain

References

${ }^{1}$ Jensen DM, Chaves DM, Grund KE. Endoscopic diagnosis and treatment of watermelon stomach. Endoscopy 2004; 36: 640-647

${ }^{2}$ Geller A, Gostout CJ, Balm RK. Development of hyperplastic polyps following laser therapy for watermelon stomach. Gastrointest Endosc 1996; 43: 54-56

${ }^{3}$ Bernstein CN, Pettigrew N, Wang KKet al. Multifocal gastric neoplasia after recurrent laser therapy for the watermelon stomach [abstract]. Can J Gastroenterol 1997; 11: $403-406$

${ }^{4}$ Yusoff I, Brennan F, Ormonde D, Laurence B. Argon plasma coagulation for treatment of watermelon stomach. Endoscopy 2002; 34: 407-410

${ }^{5}$ Probst A, Scheubel R, Wienbeck M. Treatment of watermelon stomach (GAVE syndrome) by means of endoscopic argon plasma coagulation (APC): long-term outcome [abstract]. Z Gastroenterol 2001; 39: 447 - 452

\section{Corresponding Author}

\section{S. Izquierdo Rubio, M.D.}

Digestive Disease Service

Hospital Clínico San Carlos

C/ Prof Martín Lagos s/n

28040 Madrid

Spain

Fax: + 34-91-3303785

E-mail: soniaizq@yahoo.es 